\title{
KEY TO REFERENCES
}

Except for an occasional citation from The Notebook of William Blake: A Photographic and Typographic Facsimile, ed. David V. Erdman, all quotations of Blake's writings are from The Complete Poetry and Prose of William Blake, ed. David V. Erdman, designated as E. The Oxford Standard Authors edition of Blake's Complete Writings, ed. Geoffrey Keynes, remains a necessary tool for scholarship (because the Blake Concordance, ed. David V. Erdman, is cued to it); I have therefore cited it as well, designating it as $\mathrm{K}$. Thus, whenever a text is referred to by its typography and place in $\mathrm{E}$, its place in $\mathrm{K}$ is also given. Many references, however, are listed only by the title and plate number of Blake's works, which are abbreviated as follows:

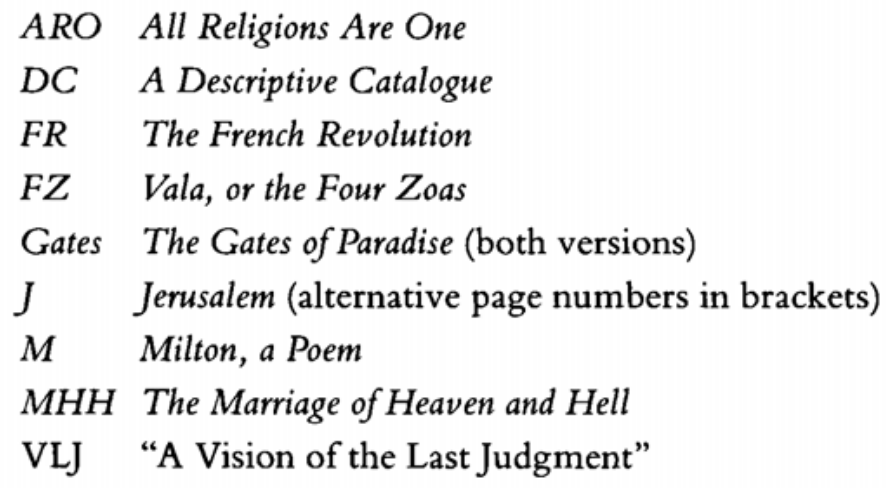

Note that in the cases of Milton and Jerusalem I offer variant page numberings (separated by a slash) when referring to plates whose positions shifted in alternate copies.

References to Bunyan's work are from the following two texts: The Pilgrim's Progress from This World to That Which Is To Come, ed. James Blanton Wharey, $2 \mathrm{~d}$ ed. rev. Roger Sharrock (Oxford: Clarendon Press, 1960), abbreviated as PP; and Grace Abounding to the Chief of Sinners, ed. Roger Sharrock (Oxford: Clarendon Press, 1962), abbreviated as GA. 
